\title{
Research On The Development Trend Of Books' Publishing In China
}

\author{
Xiao-Feng ZHU ${ }^{1, a}$, Xi-Dan Yang ${ }^{2, b}$, Shu-Yang ZHANG ${ }^{3, c}$ and Xi TIAN ${ }^{4, d}$ \\ ${ }^{1}$ Department of Basic Science, Beijing Institute of Graphic Communication, Beijing, China \\ ${ }^{2,3}$ School of Economics and Management, Beijing Institute of Graphic Communication, \\ Beijing, China \\ ${ }^{4}$ School of Information Engineering, Beijing Institute of Graphic Communication, Beijing, China \\ azhuxiaofeng@bigc.edu.cn
}

Keywords: Statistical Analysis, Regression Analysis, Books.

\begin{abstract}
First of all, we understood the present challenges and competitions which the development of the publishing industry is facing. Then we analyzed the indicators which affect the development of the publishing industry. After that, we collected the indicators of the three major publications of our country published in the past 25 years, and by using the main factor analysis method, the primary indicator of China publishing industry is considered to be the number of total printed sheets. Finally, the authors made models through methods like AHP, Regression Analysis, Trend Equation Model Analysis, Exponential Growth Model Analysis, to analyze and predict the number of total printed sheets of the books in 1987-2011 year. In order to provide useful data for the relevant research departments, and promote development of the publishing industry in China.
\end{abstract}

\section{Introduction}

Nowadays, the publishing industry of our country has become industrialized and large-scaled, and has more regularity in its development. However, as a particular industry, the publishing industry has its own feature in the development. One is that the trend of developing and changing is complicated. Another is that a lot of indicators are needed during the quantitative analysis. And the other is that there are nonlinear relationships between different data. Therefore, how to create a suitable mathematical model, and providing necessary and valuable analyzed data for the publishing industry of our country by the quantitative analysis of it and the searching of the regular information in the developing process, has become a significant issue of the growth of the publishing industry.

In China, the publishing industry belongs to a special kind of industry which produces and sales cultural products. On one hand, it has a sacred mission of culture accumulation and heritage of civilization. On the other hand, the product of the publishing industry has the general attributes of merchandise, which must be exchanged to implement its value and achieve its political and cultural mission, is for filling the growing spiritual and cultural need of people.

\section{Prediction of Books Publishing}

There are many kinds of publications, which contains traditional publications, like books, newspapers and periodicals; electronic publications, like floppy disk, CD-ROM, interactive CD-ROM, and Photo CD, etc. Due to the short developing period of electronic publications, the regularity of its data is weak, so we the authors mainly analyze and research the indicators of traditional publications. In order to research the growth trend of books publishing, we investigate the indicator data in the publishing industry of books in our country from 1987 to 2011 (Table 1), nearly 25 years in the past, and we draw the data curve of it ( Fig. 1).

From Fig. 1, we can say that the trend of books publishing in our country is rising up, and has less volatility. So we use Trend Equation Fitting Method to predict the data of books publishing. 
Table 1 Statistics of publishing data

(Unit: hundred million sheets)

\begin{tabular}{|c|c|c|c|c|c|c|c|c|c|c|c|c|c|}
\hline Year & 1987 & 1988 & 1989 & 1990 & 1991 & 1992 & 1993 & 1994 & 1995 & 1996 & 1997 & 1998 & 1999 \\
\hline \multirow{2}{*}{ Books } & 261. & 269. & 243. & 232. & 266. & 280. & 282. & 297. & 316. & 360. & 364. & 373. & 391. \\
& 3 & 0 & 6 & 1 & 1 & 0 & 3 & 2 & 8 & 5 & 0 & 6 & 4 \\
\hline Year & 2000 & 2001 & 2002 & 2003 & 2004 & 2005 & 2006 & 2007 & 2008 & 2009 & 2010 & 2011 & \\
\hline \multirow{2}{*}{ Books } & 376. & 406. & 456. & 462. & 465. & 493. & 512. & 486. & 561. & 565. & 604. & 634. & \\
& 2 & 1 & 4 & 2 & 6 & 3 & 0 & 5 & 1 & 5 & 7 & 5 & \\
\hline
\end{tabular}

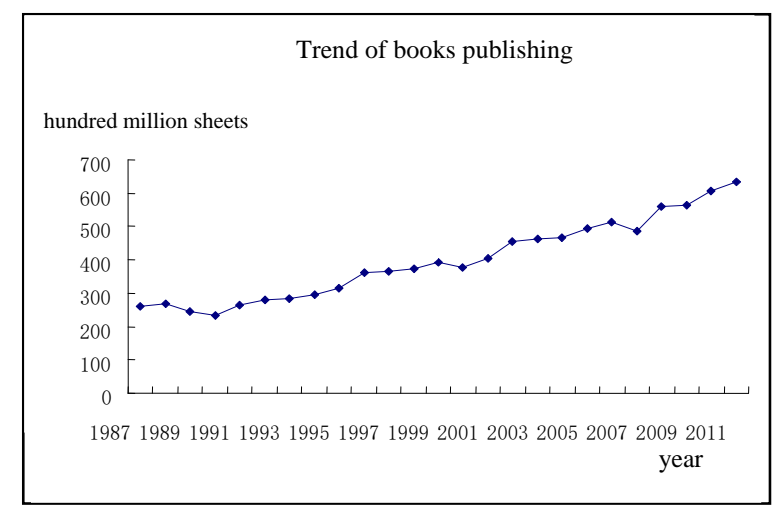

Figure 1 Trend of books publishing

Brief Introduction of Trend Equation Fitting Method. Trend equation fitting method is a long-term trend to determine the phenomenon by fitting a time $t$ as the explanatory variate, the investigated indicators are explanatory variables regression equation. The best advantage is: it can not only determine the time series trend value each period, and the trend of the fitting equation also has extended extrapolation function, you can direct prediction equations based on trends. Long-term trends can be divided into linear and nonlinear trend trends. Trend shave different shapes, the fitting trend equation will have different forms.

Due to the time series by approximately the same amount of growth, the long-term trends can be approximated by a straight line to describe, with linear time series trend, you can use the following form of the linear trend equation to describe

$$
\hat{y}_{t}=a+b t \text {. }
$$

$\hat{y}_{t}$ for time-series trends in value; $t$ for the time (take $t=1,2, \ldots, \mathrm{n}$ ); $a$ is the intercept of the trend lines and trends to represent $t=0$ values (that is, set initial value for long-term trends in time-series), $b$ is the slope of the trend line, $t$ represents time, each change $a$ flat trend changes in the value of average weight.

Method of estimating parameters $a, b$ in the linear trend equation is typically the least square method, the formula with parameters in the linear regression equation formula of the same, that is calculated as

$$
\left\{\begin{array}{l}
b=\frac{n \sum t y_{t}-\sum t \sum y_{t}}{n \sum t^{2}-\left(\sum t\right)^{2}} . \\
a=\bar{y}-b \bar{t}
\end{array} .\right.
$$

Building and Solving in Trend Equation Fitting Method. We can see from the curve of the printed sheets of books that the annually change of the printed sheets data is like a straight line. So it could be fitted in linear trend equation. Take the $t=1,2, \ldots, 25$, according to Eq. 1 , we can calculate the estimated value of the parameter $a=190.43, b=16.003$, which demands a linear trend equation

$$
\hat{y}_{t}=190.43+16.003 t \text {. }
$$

According to Eq. 2, we calculated the estimated value $\hat{y}_{t}$ (Table 2) and got the fitting curve graph of the total printed sheets for books publishing (Fig. 2). 
Table 2 Trend of total printed sheets for books publishing in year 1987-2011

(Unit: hundred million sheets)

\begin{tabular}{|c|c|c|c|c|c|c|c|c|c|}
\hline year & $\mathrm{t} /$ time & $\begin{array}{c}\text { Observed } \\
\text { values }\end{array}$ & $\begin{array}{c}\text { Trend } \\
\text { values }\end{array}$ & Residuals & year & $\begin{array}{c}\text { t/tim } \\
\mathrm{e}\end{array}$ & $\begin{array}{c}\text { Observed } \\
\text { values }\end{array}$ & $\begin{array}{c}\text { Trend } \\
\text { values }\end{array}$ & Residuals \\
\hline 1987 & 1 & 261.247 & 206.433 & 54.814 & 2000 & 14 & 376.200 & 414.472 & -38.272 \\
\hline 1988 & 2 & 269.027 & 222.436 & 46.591 & 2001 & 15 & 406.100 & 430.475 & -24.375 \\
\hline 1989 & 3 & 243.618 & 238.439 & 5.179 & 2002 & 16 & 456.400 & 446.478 & 9.922 \\
\hline 1990 & 4 & 232.055 & 254.442 & -22.387 & 2003 & 17 & 462.200 & 462.481 & -0.281 \\
\hline 1991 & 5 & 266.107 & 270.445 & -4.338 & 2004 & 18 & 465.600 & 478.484 & -12.884 \\
\hline 1992 & 6 & 280.037 & 286.448 & -6.411 & 2005 & 19 & 493.300 & 494.487 & -1.187 \\
\hline 1993 & 7 & 282.261 & 302.451 & -20.19 & 2006 & 20 & 512.020 & 510.490 & 1.530 \\
\hline 1994 & 8 & 297.160 & 318.454 & -21.294 & 2007 & 21 & 486.510 & 526.493 & -39.983 \\
\hline 1995 & 9 & 316.782 & 334.457 & -17.675 & 2008 & 22 & 561.130 & 542.496 & 18.634 \\
\hline 1996 & 10 & 360.451 & 350.460 & 9.991 & 2009 & 23 & 565.500 & 558.499 & 7.001 \\
\hline 1997 & 11 & 364.002 & 366.463 & -2.461 & 2010 & 24 & 604.740 & 574.502 & 30.238 \\
\hline 1998 & 12 & 373.617 & 382.466 & -8.849 & 2011 & 25 & 634.500 & 590.505 & 43.995 \\
\hline 1999 & 13 & 391.353 & 398.469 & -7.116 & & & & & \\
\hline
\end{tabular}

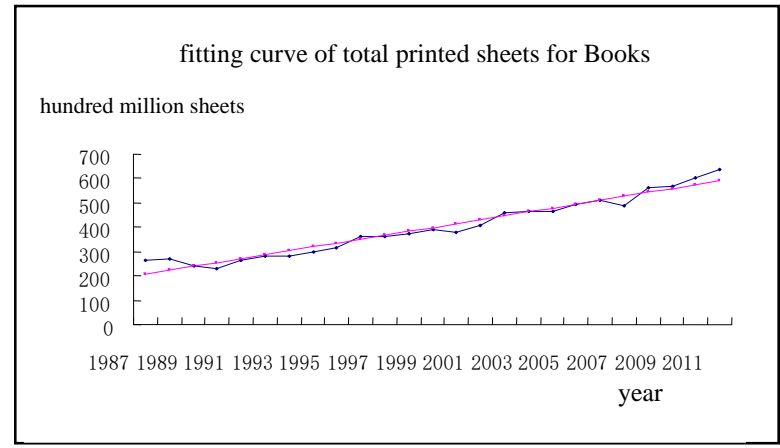

Figure 2 Fitting curve of total printed sheets for books publishing

Prediction of Books Publishing. According to the comparison of values based on actual data and trend value, we tested the trend formula, and it fits the growth. Seen from the fitting function, with the growth over time, the total number of published copies of books increased year by year and it's in linear relationship with time. On one hand, from the micro-economic point of view, goods are divided into essential goods and exceeding necessities. As its name implies, the former is indispensable to maintaining daily life, such as clothing, food, shelter and so on; the latter is relatively dispensable in everyday life, such as reading, traveling, listening to music, and so on. Books as exceeding necessities, with the growth of the national economy and people's income, consumption levels are rising, the consumption of books every year is in an increasing trend. Moreover, with the advent of globalization, our countryapplied "bringing in and going out" policy, introduced a number of foreign-language books in recent years, and then translated and published, liked by the majority of people, resulting in the increasing of the published books.

Based on Eq. 2, we can predict from 2012 to 2016 (late 12th 5-year and early 13th 5-year) for the next five years, the total number of published books, as shown in Table 3. Which actual data in 2012 is 66.699 billion copies, compared with the forecast data, the difference is very small, only $9.06 \%$. This indicates that the predicted data of this model is accurate. 
Table 3 The predicted data of books publishing from 2012 to 2016

(Unit: hundred million sheets)

\begin{tabular}{|c|c|c|c|c|c|}
\hline Year & 2012 & 2013 & 2014 & 2015 & 2016 \\
\hline $\begin{array}{c}\text { Sheets of published books } \\
\text { (hundred million) }\end{array}$ & 606.508 & 622.511 & 638.514 & 654.517 & 670.52 \\
\hline
\end{tabular}

\section{Summary}

Two fast-rising GDP growth phase in China is the earlier 1980s of the 20th century and the middle 90s, the top speed was in 1984 and 1992.The speed of the growth of total printed copies in China reached a top for the first time in 1985, but since 1990 the continuous growth of the total copies stayed in the same direction as the growth of the GDP after the 1990s of the 20th century. This indicates that the development of publications made a certain contribution to China's GDP growth.

For nearly 30 years, China's publishing industry have gradually achieved the transformation from "bringing in" to "going out", and the international competitiveness increases. But with the advent of the information age, China's publishing industry also faces a lot of competition and challenges. From the perspective of the statistical analysis, we analyzed the indicators data of books publishing in1987-2011, and forecasted the data of books publishing in the late Twelve-Five and early Thirteen-Five for the next five years. I hope to help the future development of the publishing industry.

\section{Acknowledgement}

The research was supported by the Project for Building Excellent Teaching Team of Beijing Institute of Graphic Communication, Teaching Reform Project of Beijing Municipal for the higher education (2013-lh08), Key Teaching Reform Project of Beijing Institute of Graphic Communication, Foundation of Beijing Municipal Education Commission (KM2014100150012), Construction Project of Teachers of Beijing Municipality (Young Talent Program Selected Staff).

\section{References}

[1] Zhen-Sheng HAO, The report of development for Chinese publishing industry in 2009-2010, China Books Press, 2010.

[2] Guan-Yi WANG, Yu-Hong HUA, Study on the performance evaluation of Chinese publishing industry, China Financial and Economic Press, 2010.

[3] The writing group of mathematical model, Mathematical model, South China University of Technology Press, 2001.

[4] Wu-Yi ZENG and Hong-Ye XIAO, Statistics Introduction, Science Press, 2012.

[5] Xi-Zu YAN, Zhong-Min SONG and Chun-Jia BI, Mathematical modeling and experiment, Science Press, 2009.

[6] Information on http://www.cnki.net.

[7] Information on http://www.stats.gov.cn.

[8] http://www.doc88.com/p-892244711319.html.

[9] http://blog.sina.com.cn/s/blog_1757f60af0100zwfb.html.z 